\title{
Paediatric haemolytic uraemic syndrome related to Shiga toxin-producing Escherichia coli, an overview of 10 years of surveillance in France, 2007 to 2016
}

Mathias Bruyand ${ }^{1}$, Patricia Mariani-Kurkdjian², Simon Le Hello ${ }^{3}$, Lisa-A King ${ }^{4}$, Dieter Van Cauteren ${ }^{1}$, Sophie Lefevre ${ }^{3}$, Malika Gouali $^{3}$, Nathalie Jourdan-da Silva ${ }^{1}$, Alexandra Mailles ${ }^{1}$, Marie-Pierre Donguy ${ }^{5}$, Estelle Loukiadis ${ }^{6,7}$, Delphine SergentetThevenot ${ }^{6,7}$, Chantal Loirat ${ }^{8}$, Stéphane Bonacorsi ${ }^{2}$, François-Xavier Weill ${ }^{3}$, Henriette De Valk ${ }^{1}$, Réseau français hospitalier de surveillance du SHU pédiatrique 9

1. Santé publique France, Saint Maurice, France

2. Service de Microbiologie, Hôpital Robert-Debré, AP-HP, Paris, France

3. Institut Pasteur, Unité des Bactéries Pathogènes Entériques, Centre National de Référence des E. coli, Shigella et Salmonella, Paris, France

4. Santé publique France, Rennes, France

5. Ministry of Agriculture, Agrifood, and Forestry, Paris, France

6. Université de Lyon, VetAgro Sup, Laboratoire National de Référence pour les Escherichia coli, Marcy l'Etoile, France

7. Université de Lyon, CNRS, INRA, Université Claude Bernard Lyon 1, VetAgro Sup, Laboratoire d’Ecologie Microbienne, Villeurbanne, France

8. Pediatric Nephrology Department, University Hospital Robert Debré, Paris, France

9. Members of the Réseau français hospitalier de surveillance du SHU pédiatrique have been listed at the end of the article

Correspondence: Mathias Bruyand (mathias.bruyand@santepubliquefrance.fr)

Citation style for this article:

Bruyand Mathias, Mariani-Kurkdjian Patricia, Le Hello Simon, King Lisa-A, Van Cauteren Dieter, Lefevre Sophie, Gouali Malika, Jourdan-da Silva Nathalie, Mailles Alexandra, Donguy Marie-Pierre, Loukiadis Estelle, Sergentet-Thevenot Delphine, Loirat Chantal, Bonacorsi Stéphane, Weill François-Xavier, De Valk Henriette, Réseau français hospitalier de surveillance du SHU pédiatrique. Paediatric haemolytic uraemic syndrome related to Shiga toxin producing Escherichia coli, an overview of 10 years of surveillance in France, 2007 to 2016. Euro Surveill. 2019;24(8):pii=1800068. https://doi.org/10.2807/1560-7917.ES.2019.24.8.1800068

Introduction: Haemolytic uraemic syndrome (HUS) related to Shiga toxin-producing Escherichia coli (STEC) is the leading cause of acute renal failure in young children. In France, HUS surveillance in children aged 15 years was implemented starting from 1996. Aim: We present the results of this surveillance between 2007 and 2016. Methods: A voluntary nationwide network of 32 paediatric departments notifies cases. Two national reference centres perform microbiological STEC confirmation. Results: Over the study period, the paediatric HUS incidence rate (IR) was 1.0 per 100,000 children-years, with a median of 116 cases/year. In 2011, IR peaked at 1.3 per 100,000 children-years, and decreased to 1.0 per 100,000 children-years in 2016. STEC 0157 associated HUS peaked at 37 cases in 2011 and decreased to seven cases in 2016. Cases of STEC 026-associated HUS have increased since 2010 and STEC 080 associated HUS has emerged since 2012, with 28 and 18 cases respectively reported in 2016. Four STEC-HUS food-borne outbreaks were detected (three STEC 0157 linked to ground beef and raw-milk cheese and one STEC 0104 linked to fenugreek sprouts). In addition, two outbreaks related to person-to-person transmission occurred in distinct kindergartens (STEC 0111 and 026). Conclusions: No major changes in HUS IRs were observed over the study period of 10 years. However, changes in the STEC serogroups over time and the outbreaks detected argue for continuing epidemiological and microbiological surveillance.

\section{Introduction}

Shiga toxin-producing Escherichia coli (STEC) causes bloody diarrhoea, which is complicated in $5-15 \%$ of paediatric patients by haemolytic uraemic syndrome (HUS) [1]. HUS is defined by the triad of mechanical haemolytic anaemia, thrombocytopenia and acute kidney injury [1]. STEC related HUS, also called postdiarrhoeal HUS, is the main cause of acute renal failure in young children [1]. The thrombotic microangiopathy process mainly affects the kidney, potentially resulting in long-term sequelae. Other organs such as the intestine, central nervous system and heart may also be affected [2]. Ruminants, especially cattle, are the main reservoirs for the highly virulent STEC 0157 strain [3], as well as other HUS-associated non-0157 strains [4]. STEC infection routes are ingestion of contaminated food or water, contact with an animal or an environment contaminated by STEC (such as bathing water or soil in the proximity of ruminants) $[5,6]$ or personto-person transmission, which is frequently observed due to the low infectious dose of STEC ( 11,000 organisms) [7]. Due to the outbreak potential and the severe morbid conditions related to STEC HUS, STEC infection represents an important public health concern $[1,8,9]$. Various options are available for surveillance, which can be based on case notification on a mandatory or 


\section{FIGURE 1}

Numbers of paediatric haemolytic uraemic syndrome cases reported to the surveillance system and numbers of outbreaks detected, France, 2007-2016 ( $\mathrm{n}=1,215$ cases)

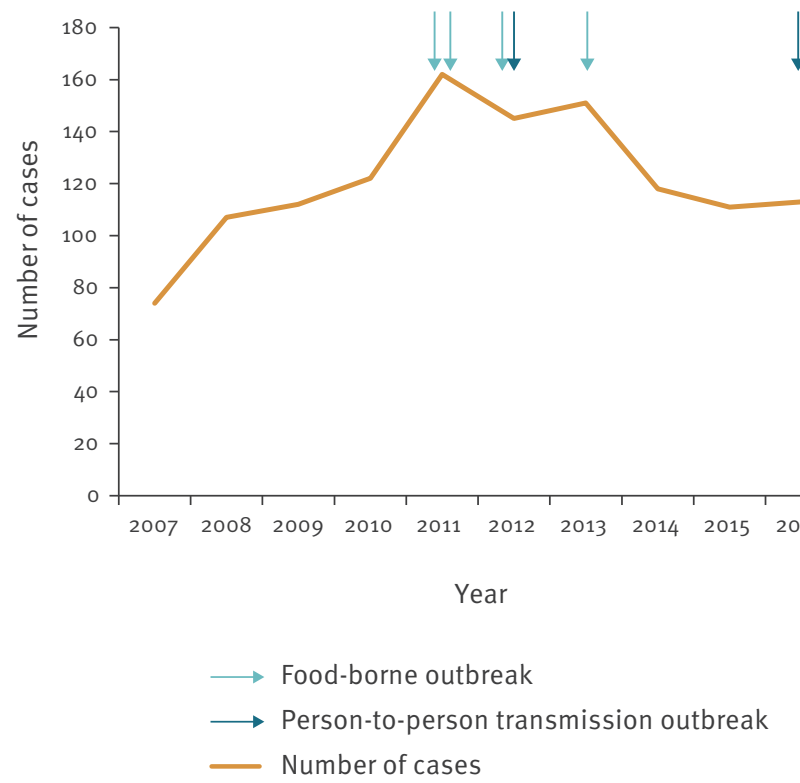

HUS: haemolytic uraemic syndrome.

The numbers of children with HUS were one and 18 during the two outbreaks in 2011, respectively; four and four during the two outbreaks in 2012; four during the outbreak in 2013 and one during the one in 2016 .

voluntary basis, and microbiological surveillance of STEC infection relying on a National Reference Centre (NRC) for human samples [10-12]. In France, STEC surveillance relies on voluntary HUS surveillance in children aged $<15$ years [13-15]. STEC identification in stool samples is not routinely performed by medical laboratories in France, however any laboratory in the country can send a stool sample to the associated laboratory of the NRC for STEC screening, highlighting the key role of the NRC for human samples in STEC surveillance.

This report presents the results of the French paediatric HUS surveillance over a 10-year period, from 1 January 2007 to 31 December 2016.

\section{Methods}

Description of the French paediatric haemolytic uraemic syndrome surveillance system

The French paediatric HUS surveillance system is implemented since 1996. It is coordinated by Santé publique France, the French national public health agency.

The objectives of the surveillance system are to monitor the spatial and temporal trends of paediatric HUS incidence, describe the characteristics of cases, and detect clusters of cases to guide prevention and control measures.

Children aged less than 15 years presenting with the triad of acute renal failure, mechanical haemolytic anaemia, and thrombocytopenia fulfil the case definition criteria and are notified to Santé publique France. Acute renal failure is defined as serum creatinine levels above $60 \mu \mathrm{mol} / \mathrm{L}$ in children aged less than 2 years and above $70 \mu \mathrm{mol} / \mathrm{L}$ in older children. Mechanical haemolytic anaemia is defined as haemoglobin level lower than $10 \mathrm{~g} / 100 \mathrm{~mL}$, with a proportion of schistocytes $\geq 2 \%$. Thrombocytopenia is defined by a platelet count lower than $150,000 / \mu \mathrm{L}$.

Thirty-two French paediatric departments distributed throughout France (excluding the overseas departments), including all the 21 university hospital units specialised in paediatric nephrology, are involved in the surveillance since 1996. Physicians notify HUS cases in real time on a voluntary basis to Santé publique France. In addition, any physician or microbiologist in France, may notify cases of HUS or STEC infection to Santé publique France, regardless of their routine involvement in the surveillance system. Notified cases reporting travel abroad during the 7 days preceding onset of symptoms are considered as imported and not included in the surveillance reports.

\section{Confirmation of Shiga toxin- \\ producing Escherichia coli infection or \\ environmental contamination}

The NRC for Escherichia coli, Shigella and Salmonella in human samples (Institut Pasteur, Paris, France) and its associated laboratory (Microbiology laboratory, University Hospital Robert Debré, Paris, France) confirm STEC infection. Confirmation is done through the detection by PCR in stool samples of the virulence genes for the Shiga toxins (stx1 and stx2 genes), the gene for the outer membrane protein intimin (eae for $E$. coli attaching and effacing), the enterohemolysin gene $(e h x A)$, and the 0 -antigen biosynthesis genes of the 10 most frequent STEC serogroups affecting humans in France $\left(\mathrm{O}_{157}, \mathrm{O} 26, \mathrm{O}_{145}, \mathrm{O}_{55}, \mathrm{O}_{103}, \mathrm{O}_{104}, \mathrm{O}_{111}\right.$, 091, 0121, and 080) [15]. STEC screening in stool is considered positive if stx 1 and/or stx 2 genes are detected. Culture is performed on all stx positive stools to characterise STEC strains by serogrouping and to test for the same virulence genes. Non-typeable STEC strains are characterised by using PCR-restriction fragment length polymorphism of the 0 operon ( $r f b-R F L P$ ) and sequencing of the flagellin gene (fliC) $[16,17]$. Investigations for the presence of STEC strains in food and environmental samples are performed by the National Reference Laboratory (NRL) for E. coli isolated from food and environmental sources (VetAgro Sup, Lyon, France) according to the XP CEN ISO/TS 13136:2012 method [18]. Serotyping of the STEC strains isolated is performed by PCR as described previously $[16,17]$. 


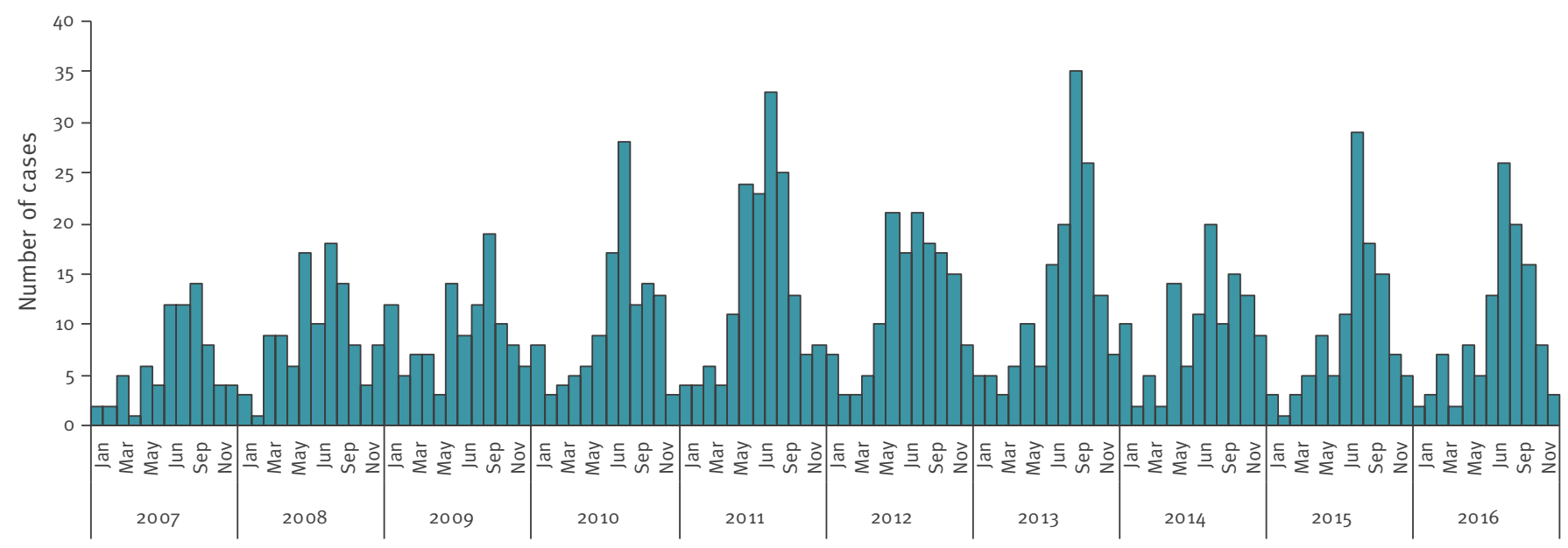

Month and year of diagnosis

\section{Information routinely collected}

We systematically collect data on the date of symptom onset, gastrointestinal symptoms, biological parameters related to HUS and STEC strain, and outcome using a standardised notification form. Information about related cases of HUS or diarrhoea, and exposure to traditional STEC risk factors in the 2 weeks preceding HUS diagnosis (raw milk dairy or ground meat consumption, contact with farm animals, bathing in a pool or surface water) are collected as well. Epidemiological investigations are not routinely performed to identify the infection source of sporadic cases. Thus, information routinely gathered on the notification form allows describing cases' characteristics rather than identifying cases' infection sources.

\section{Investigations of suspected clusters}

Any suspicion of a cluster of HUS or diarrhoea cases potentially due to STEC infection leads to an epidemiological investigation to confirm or rule out an outbreak, identify the source of infection and guide control measures. We assess potential STEC exposures within the 7 days preceding symptom onset using a detailed trawling questionnaire completed with the parents or caretakers of the child. For the specific cases related to the STEC 0104: $\mathrm{H}_{4}$ strain, the investigation covers the 14 days preceding symptom onset, as the incubation period for this specific serogroup may exceed 1 week $[19,20]$.

An outbreak is defined as two or more HUS or STEC infection cases with an epidemiological link (common exposure or person-to-person transmission). In an outbreak context, the NRC for human samples and the NRL for $E$. coliisolated from food and environmental sources are involved through confirming STEC infection in cases, identifying STEC in the suspected sources, and comparing STEC strains isolated in cases' stools and in suspected sources of infection. The strain comparisons are performed using the Standard PulseNet PFGE protocol for E. coli $\mathrm{O}_{157}$ [21], and increasingly, since 2016, using whole genome sequencing (WGS) methods.

\section{Population estimates}

Population estimates provided by the National Institute for Statistics and Economic Studies were used to assess incidence rates of reported HUS (IR) [22].

\section{Results}

From 2007 to 2016, a median of 116 paediatric HUS cases was reported each year (minimum: 74; maximum: 162) (Figure 1). The highest annual IR was reported in 2011 with an IR of 1.3 cases per 100,000 children-years, in 2016 the IR was 1.0 case per 100,000 children-years. During the study period, a total of 1,215 cases were notified (IR of 1.0 case per 100,000 children-years), including $32(3 \%)$ who were part of six recognised outbreaks. Of these outbreaks, four were food-borne, including two in 2011, one in 2012 and one in 2013. A temporary increase of the reported number of sporadic cases (not linked to the outbreak) was observed during the months following each of these outbreaks. The remaining two outbreaks involved person-to-person transmission and occurred in two different kindergartens in 2012 and 2016 (Figure 1).

Seasonality was consistently observed, with the majority of cases being reported in the summer months (Figure 2). In this period, the number of notifications was usually two to three times higher compared with the winter months.

Paediatric HUS IR demonstrated an important spatial heterogeneity. During the study period, the most affected regions were located in north-west and centraleastern France (Basse-Normandie and Franche-Comté), 


\section{FIGURE 3}

Incidence of paediatric haemolytic uraemic syndrome by region, France, 2007-2016

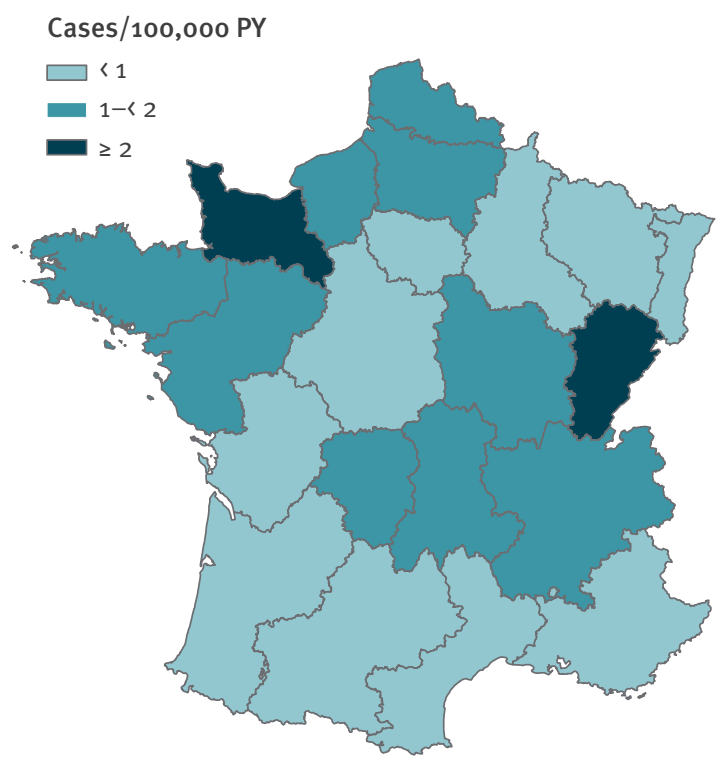

PY: children-years.

with an IR more than double the least affected regions (south, centre and north-east of France) (Figure 3).

In children aged less than 6 months, IR was 0.8 case per 100,000 children-years. IR peaked to 3.3 cases per 100,000 children-years in children aged 6 months to 2 years ( 35 months) and then decreased with increasing age: 1.2 cases per 100,000 children-years in children aged 3 to 5 years, 0.5 case per 100,000 children-years in those aged 6 to 10 years and 0.2 case per 100,000 children-years in those aged 11 to 14 years. There was no difference in $I R$ according to sex (IR of 1.0 case per 100,000 children-years in boys and 1.1 cases per 100,000 children-years in girls).

Median age at HUS diagnosis was 30 months (interquartile range (IQR): 17-62). Over the entire study period, HUS was preceded by diarrhoea in 1,099 (90\%) cases, of whom 545 (50\%) had bloody diarrhoea (Table 1). The median delay between diarrhoea onset and HUS diagnosis was 6 days (IQR: 4-8). During the entire study period, acute renal failure was observed in $71 \%$ of cases, median plasma creatinine level was 188 $\mu \mathrm{mol} / \mathrm{L}$ (IQR: 73-389) and median blood platelet count

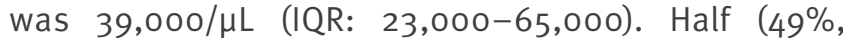
$592 / 1,215)$ of patients required blood transfusion, and $32 \%(389 / 1,215)$ required dialysis. Eleven deaths (0.9\% of cases) were reported. No major changes were observed in the characteristics of cases over the study period (Table 1). Renal failure seemed to be more frequent in $2007-08$ ( $86 \%$ vs $64 \%$ to $71 \%$ between 2009 and 2016). Over the study period, the highest values of creatininaemia (median: $217 \mu \mathrm{mol} / \mathrm{L}$; IQR: 103-440) were also observed in 2007-08 (Table 1). In 2007$08,38 \%$ of children had dialysis, and this proportion ranged between $29 \%$ and 33\% between 2009 and 2016 (Table 1).

Stool analysis results were available for 942 cases, $730(77 \%)$ of them had a positive STEC result screening. Among 689 cases with a positive STEC screening for whom detailed information was available, the virulence genes $s t \times 1, s t \times 2$, eae and $e h x A$ were carried by $12 \%$ (85/689), 98\% (675/689), 88\% (603/689) and $59 \%(409 / 689)$ of the cases respectively. Both stx1 and stx2 were detected in $10 \%(71 / 689)$ instances.

Among 942 cases with a stool analysis result available, STEC serogroup was identified in 496 instances. During the study period, the most frequent STEC serogroups identified were 0157 (212 cases, $23 \%$ of 942 cases with a stool analysis), 026 (106 cases, $11 \%$ ) and 080 (73 cases, $8 \%$ ) (Table 1). The most frequents serogroups following the top three were 0111 (18 cases), 0145 and 055 (14 cases each).

Major changes were observed in STEC serogroups over the study period (Figure 4). The number of paediatric HUS cases with a STEC 0157 evidenced in stool increased until 2011 (37 cases) and subsequently decreased to seven cases in 2016. From 2014 to 2016, the annual total number of paediatric HUS cases reported remained stable, while the number of cases related to STEC 0157 continued to decrease. The $0_{26} 6$ serogroup increased after 2010 (5 cases), in 2016 it was the main serogroup evidenced in stool (28 cases). The STEC 080 strain clearly emerged after 2012 to become the main serogroup evidenced in HUS cases' stool in 2015 (19 cases). The number of cases affected by STEC 080 remained stable in 2016 (18 cases).

Four food-borne outbreaks were detected, involving a total of 56 reported cases including 34 cases of HUS (27 children and 7 adults) $[19,23,24]$. A STEC 0104: 44 outbreak caused by fenugreek detected in 2011 was linked to a large German outbreak, and involved 24 cases in France, of whom six adults and one child had HUS $[19,20]$. A second outbreak linked to the consumption of contaminated ground beef distributed as frozen burgers also occurred in 2011. Eighteen paediatric HUS cases infected with a sorbitol-fermenting STEC O $157: \mathrm{H}_{7}$ or a STEC $\mathrm{O}_{177}: \mathrm{H}_{2} 5$ were identified by the outbreak investigation [24]. The third outbreak detected in 2012 was related to STEC 0157:H7. Six cases including four paediatric HUS cases were linked to the consumption of contaminated fresh ground beef [23]. In 2013, eight cases including four paediatric HUS cases were linked to an outbreak associated with the consumption of raw milk cheese, a non-sorbitol fermenting STEC 0157: $\mathrm{H}$ - was involved. In the two outbreaks related to contaminated ground beef consumption, enhanced 
TABLE 1.

Characteristics of paediatric HUS cases reported to the French HUS surveillance system, France, 2007-2016 (n=1,215 cases)

\begin{tabular}{|c|c|c|c|c|c|c|c|c|c|c|c|c|c|c|c|c|c|c|}
\hline \multirow{2}{*}{ Characteristic } & \multicolumn{3}{|c|}{$2007-2008$} & \multicolumn{3}{|c|}{$2009-2010$} & \multicolumn{3}{|c|}{$2011-2012$} & \multicolumn{3}{|c|}{$2013-2014$} & \multicolumn{3}{|c|}{$2015-2016$} & \multicolumn{3}{|c|}{ Total } \\
\hline & $\begin{array}{l}\text { Median } \\
\text { (IQR) }\end{array}$ & $\mathrm{n}$ & $\%$ & $\begin{array}{l}\text { Median } \\
\text { (IQR) }\end{array}$ & $\mathrm{n}$ & $\%$ & $\begin{array}{l}\text { Median } \\
\text { (IQR) }\end{array}$ & $\mathrm{n}$ & $\%$ & $\begin{array}{l}\text { Median } \\
\text { (IQR) }\end{array}$ & $\mathrm{n}$ & $\%$ & $\begin{array}{c}\text { Median } \\
\text { (IQR) }\end{array}$ & $\mathrm{n}$ & $\%$ & $\begin{array}{l}\text { Median } \\
\text { (IQR) }\end{array}$ & $\mathrm{n}$ & $\%$ \\
\hline HUS & NA & 180 & 100 & NA & 234 & 100 & NA & 307 & 100 & NA & 269 & 100 & NA & 225 & 100 & NA & 1,215 & 100 \\
\hline Male sex & NA & 97 & 54 & NA & 112 & 48 & $\mathrm{NA}$ & 164 & 53 & $\mathrm{NA}$ & 121 & 45 & NA & 99 & 44 & NA & 593 & 49 \\
\hline Age (months) & $33(19-61)$ & NA & NA & $31(18-60)$ & NA & NA & $\begin{array}{c}35 \\
(18-71)\end{array}$ & NA & NA & $\begin{array}{c}29 \\
(15-59)\end{array}$ & NA & NA & $\begin{array}{c}24 \\
(14-54)\end{array}$ & NA & NA & $\begin{array}{c}30 \\
(17-62)\end{array}$ & NA & NA \\
\hline Diarrhoea & NA & 171 & 95 & NA & 220 & 94 & NA & 277 & 90 & NA & 242 & 90 & NA & 189 & 84 & NA & 1,099 & 90 \\
\hline Bloody diarrhoea & NA & 99 & 55 & NA & 112 & 48 & NA & 155 & 50 & NA & 92 & 34 & NA & 87 & 39 & NA & 545 & 45 \\
\hline $\begin{array}{l}\text { Delay diarrhoea to } \\
\text { HUS (days) }\end{array}$ & $5(4-7)$ & NA & NA & $6(4-9)$ & NA & NA & $6(4-9)$ & NA & NA & $6(4-9)$ & NA & NA & $6(4-9)$ & NA & NA & $6(4-8)$ & NA & NA \\
\hline $\begin{array}{l}\text { Acute renal } \\
\text { failure }^{a}\end{array}$ & NA & 155 & 86 & NA & 165 & 71 & NA & 210 & 68 & NA & 171 & 64 & NA & 157 & 70 & NA & 858 & 71 \\
\hline $\begin{array}{l}\text { Creatininaemia } \\
(\mu \mathrm{mol} / \mathrm{L})\end{array}$ & $\begin{array}{c}217 \\
03-440)\end{array}$ & NA & NA & $\begin{array}{c}211 \\
(78-420) \\
\end{array}$ & NA & NA & $\begin{array}{c}163 \\
(78-362) \\
\end{array}$ & NA & NA & $\begin{array}{c}161 \\
(59-397) \\
\end{array}$ & NA & NA & $\begin{array}{c}181 \\
(61-350) \\
\end{array}$ & NA & NA & $\begin{array}{c}188 \\
(73-389) \\
\end{array}$ & NA & NA \\
\hline $\begin{array}{l}\text { Platelet count } \\
(\mathrm{g} / \mathrm{L})\end{array}$ & $39(23-65)$ & NA & NA & $38(24-66)$ & NA & NA & $\begin{array}{c}39 \\
(23-65) \\
\end{array}$ & NA & NA & $\begin{array}{c}40 \\
(26-63) \\
\end{array}$ & NA & NA & $\begin{array}{c}38 \\
(20-63)\end{array}$ & NA & NA & $\begin{array}{c}39 \\
(23-65) \\
\end{array}$ & NA & NA \\
\hline Dialysis & NA & 69 & 38 & NA & 67 & 29 & NA & 100 & 33 & NA & 78 & 29 & NA & 75 & 33 & NA & 389 & 32 \\
\hline Blood transfusion & NA & 143 & 79 & NA & 84 & 36 & NA & 46 & 15 & NA & 158 & 59 & NA & 161 & 72 & NA & 592 & 49 \\
\hline Death & NA & 2 & 1.1 & NA & 1 & 0.4 & NA & 5 & 1.6 & NA & 1 & 0.4 & NA & 2 & 0.9 & NA & 11 & 0.9 \\
\hline Stool analysis & NA & 123 & 100 & NA & 170 & 100 & NA & 244 & 100 & NA & 225 & 100 & NA & 180 & 100 & NA & 942 & 100 \\
\hline E. coli $\mathrm{O}_{157}$ & NA & 38 & 31 & NA & 40 & 24 & NA & 65 & 27 & NA & 50 & 22 & NA & 19 & 11 & NA & 212 & 23 \\
\hline E. coli 080 & NA & 0 & 0 & NA & 6 & 4 & NA & 7 & 3 & NA & 23 & 10 & NA & 37 & 21 & NA & 73 & 8 \\
\hline E. coli $\mathrm{O}_{26}$ & NA & 9 & 7 & NA & 14 & 8 & NA & 23 & 9 & NA & 21 & 9 & NA & 39 & 22 & NA & 106 & 11 \\
\hline stx1 & NA & 9 & NA & NA & 8 & NA & $\mathrm{NA}$ & 24 & $\mathrm{NA}$ & $\mathrm{NA}$ & 27 & NA & NA & 17 & NA & $\mathrm{NA}$ & 85 & $\mathrm{NA}$ \\
\hline stx2 & NA & 64 & NA & NA & 101 & NA & NA & 175 & NA & NA & 179 & NA & NA & 156 & NA & NA & 675 & NA \\
\hline eae & NA & 53 & NA & NA & 90 & NA & NA & 163 & NA & NA & 161 & NA & NA & 136 & NA & NA & 603 & NA \\
\hline ehxA & NA & NA & NA & NA & 37 & NA & NA & 103 & NA & NA & 146 & NA & NA & 123 & NA & NA & 409 & NA \\
\hline
\end{tabular}

eae: Escherichia coli attaching and effacing gene; E. coli: Escherichia coli; ehxA: enterohemolysin gene; HUS: haemolytic uraemic syndrome; IQR: interquartile range; NA: not available; stx: Shiga toxin gene.

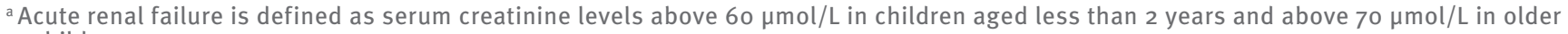
children.

trace-back investigations were performed and led to control measures which consisted of withdrawal and recall of products.

In November 2012, a STEC O111 outbreak occurred in a kindergarten in Brittany. Six confirmed cases were reported, including four paediatric HUS cases, all resulting from person-to-person transmission. Following this episode, the French high council for public health was requested to provide recommendations for the management of STEC gastroenteritis outbreaks in communities such as daycare, schools or retirement homes. These recommendations were published in January 2015 [25]. In 2016, a STEC 026:H11 outbreak occurred in a kindergarten located in the south of France. Seven confirmed cases were reported including one paediatric HUS case. All cases resulted from person-to-person transmission. WGS analysis confirmed that all cases were affected by the same STEC 026:H11 strain.

To explore infection sources of the cases affected by the emerging STEC 080 strain, and assess if this strain's emergence could be related to an outbreak, epidemiological investigations were implemented for all STEC 080 paediatric HUS cases in 2015. These investigations did not allow identifying common exposures between cases.

Among the total 1,215 paediatric HUS cases notified over the whole study period, HUS and diarrhoea cases were reported among those close to the paediatric HUS case notified in respectively $6 \%(67 / 1,215)$ and $28 \%$ $(345 / 1,215)$ instances, mostly among family members (including adults) in the same household.

Regarding exposure to the main STEC risk factors routinely collected through the notification form, consumption of raw milk was reported by $5 \%(63 / 1,215)$ of cases, raw milk cheese by $22 \%(263 / 1,215)$, ground beef by $54 \%(655 / 1,215)$ (reported as undercooked in 159 instances), bathing in a pool or surface water by $19 \%(236 / 1,215)$, and $20 \%(247 / 1,215)$ reported a contact with farm animals.

\section{Discussion}

Information collected since 1996 has allowed for the description of spatial and temporal trends in paediatric HUS incidence. In addition the description of the characteristics of cases and STEC strains has also been made possible. 
FIGURE 4

Main Shiga toxin-producing Escherichia coli serogroups causing paediatric haemolytic uraemic syndrome identified in stools, France, 2007-2016

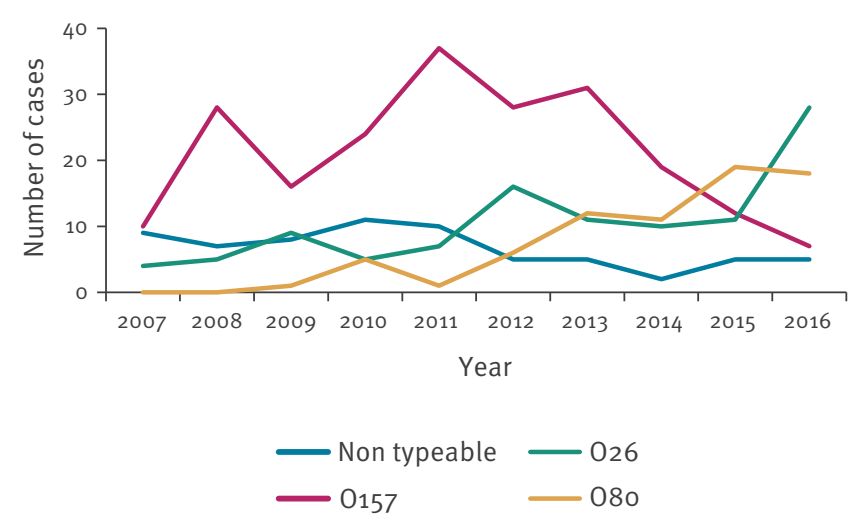

We observed strong seasonality and spatial heterogeneity in $\mathbb{I R}$, as previously documented in France between 1996 and 2006 [13]. Seasonality and spatial heterogeneity are also observed in the United States and elsewhere in Europe $[10,12]$.

An important shift occurred in France regarding STEC serogroups evidenced in paediatric HUS cases between 2007 and 2016. STEC 0157 has decreased since 2011, while the serogroup 026 has increased since 2010 and the serogroup 080 emerged in 2012. The decreasing number of STEC 0157 and the increasing numbers of STEC $0_{2} 6$ related HUS cases have also been reported elsewhere in Europe [12]. In 2005, a STEC 0157 outbreak related to the consumption of frozen beef burgers involved 69 patients including 17 HUS cases in France [26]. Following this episode, a number of preventive measures in the meat sector were implemented by the French Ministry of Agriculture, Agrifood, and Forestry $[26,27]$. Especially, STEC management measures in ground meat were enhanced and routine screening for STEC was performed more frequently by food business operators. The decrease of STEC 0157related paediatric HUS cases since 2011 in France could be a consequence of these measures, which also included detailed hygiene regulations for the production of ground meat, as cattle accounts for the main STEC 0157 reservoir.

The drivers behind the emergence of the 080 serogroup in France remain unexplained despite enhanced epidemiological investigations performed in 2015 [28]. This emergence raises specific concerns as infection by STEC 080 might lead to previously uncommon STEC related morbidity such as septicaemia [28]. Further studies are needed to better characterise this emerging strain and its determinants. Changes in the STEC serogroups might be associated with changes in the pathogenicity, as observed with the 080 serogroup [28].
In addition to classic STEC food-borne risk factors, previously not documented vehicles such as organic fenugreek seeds (STEC 0104:H4) caused outbreaks during the study period [19]. Unexpected vehicles should be taken into account in an outbreak context, especially when traditional risk factors for STEC are not outlined by the initial investigation.

The investigations performed allowed implementing control measures in several instances. Withdrawal and recall of contaminated products where set in the outbreaks linked to contaminated ground beef. Following the first outbreak due to person-to-person transmission occurring in a kindergarten, the French high council for public health provided recommendations to control STEC outbreaks in childcare facilities and schools [25]. The multidisciplinary surveillance network has involved clinicians (mainly paediatric nephrologists), epidemiologists, microbiologists and veterinary public health officers over a 20 -year period. Its stability over time is a strength of this surveillance system. It enables clinicians to inform Santé publique France about paediatric HUS cases, and to alert if STEC infection cases are suspected to be clustered.

All the French paediatric units specialised in nephrology are participants of the French paediatric HUS surveillance network since 1996. However, sporadic paediatric HUS cases may be underreported. This is suggested by the temporary increase in the number of sporadic cases notified in the months following outbreaks, probably due to raised awareness among clinicians during these periods. Sensitivity of reporting to the paediatric STEC-HUS surveillance system was estimated to be $66 \%$ in 2005 ( $95 \%$ confidence interval: 58-70) [13]. Since 2012 no major STEC HUS outbreak with media coverage occurred in France. This may have resulted in less clinicians' awareness in the latest years of the study and might have contributed to underreporting. Updated estimations of the sensitivity of the surveillance system would be valuable.

In several countries, STEC-HUS is a mandatory notifiable infection and the United States Centers for Disease Control and Prevention recommends routine stool STEC testing in all diarrhoea cases [29]. In France, most laboratories do not test STEC in stool routinely in patients with diarrhoea unless clinicians specifically request it. The lack of a standard testing panel and protocol for stool cultures and appropriate financial reimbursement of laboratories are also contributing factors to under testing that are difficult to resolve. When performed, microbiological STEC confirmation and strain characterisation relies on the NRC for human samples and its associated laboratory. This allows for the detection of any increase in paediatric STEC-HUS cases related to a given STEC serogroup, as well as clusters scattered throughout mainland France.

The expanding availability of non-culture based methods to identify a panel of infections may increase the 
number of STEC infections detected. For example, STEC detection can be achieved through multiplex PCR in stool. However, efforts should continue to perform stool culture to isolate STEC strains in all patients with positive stx screening in stool. This is the only way we can link scattered cases, especially in a context of expanding availability of WGS. Indeed, WGS enables full STEC strain characterisation and the identification of clusters that cannot be evidenced solely on the basis of epidemiological information, such as geographically scattered outbreaks, or prolonged outbreaks with a persistent source generating a limited increase in the number of cases, but over a long period of time [30]. The importance of early stool collection performed at admission of paediatric HUS cases, or rectal swab when a stool sample is not available, should be highlighted to clinicians.

\section{Conclusion}

The French paediatric HUS surveillance system has found a decline in STEC 0157 related paediatric HUS and the emergence of STEC 026 and STEC 080 in France. Six outbreaks were detected and control measures were implemented. This surveillance system is evolving, more widespread stool testing of gastroenteritis cases for STEC and routine use of WGS will improve its ability to further describe STEC strain characteristics and its capacity for outbreak detection.

Members of the Réseau français hospitalier de surveillance du SHU pédiatrique

Djamal-Dine Djeddi: Paediatric and Adolescent Medicine Departement, Centre Hospitalier Universitaire d'Amiens, Amiens, France.

Lise Allard: Paediatric Departement, Centre Hospitalier Universitaire d'Angers, Angers, France.

Sylvie Roullaud: Paediatric Departement, Centre Hospitalier d’Angoulême, Angoulême, France.

François Nobili: Paediatric Nephrology Departement, Centre Hospitalier Universitaire de Besançon, Besançon, France.

Brigitte Llanas: Paediatric Nephrology Departement, Centre Hospitalier Universitaire de Bordeaux, Bordeaux, France.

Loïc de Parscau: Paediatric Departement, Centre Hospitalier Régional Universitaire Morvan, Brest, France.

Anne-Laure Sellier-Leclerc: Paediatric Nephrology Departement, hôpital Femme-Mère-Enfant, Bron, France.

Philippe Eckart: Paediatric Departement, Centre Hospitalier Universitaire de Caen, Caen, France.

Lucie Bessenay: Paediatric Departement, Centre Hospitalier Universitaire Estaing, Clermont Ferrand, France.

Frédéric Huet: Paediatric Departement, Hôpital d’Enfants, Dijon, France.

Guylhene Bourdat-Michel: Paediatric Departement, Centre Hospitalier Universitaire de Grenoble, Grenoble, France.
Corinne Guitton: Paediatric Departement, AP-HP Centre Hospitalier Universitaire Bicêtre, Le Kremlin-Bicêtre, France.

Robert Novo: Paediatric Nephrology Departement, Hôpital Jeanne de Flandre, Centre Hospitalier Universitaire de Lille, Lille, France.

Vincent Guigonis: Paediatric Departement, Centre Hospitalier Universitaire Limoges, Limoges, France.

Marcel Guillot: Peadiatric Departement, Centre Hospitalier Robert Bisson, Lisieux, France.

Michel Tsimaratos: Paediatric Nephrology Departement, Hôpital de la Timone, Marseille, France.

Marc Fila: Paediatric Departement, Centre Hospitalier Universitaire de Montpellier, Montpellier, France.

Gwenaelle Roussey-Kessler: Paediatric Nephrology Departement, Centre Hospitalier Universitaire de Nantes, Nantes, France.

Etienne Berard: Paediatric Nephrology Departement, Centre Hospitalier Universitaire de Nice, Archet 2, Nice, France.

Tim Ulinski: Paediatric Nephrology Departement, Hôpital Armand Trousseau, APHP, Paris, France.

Chantal Loirat: Paediatric Nephrology Departement, Hôpital Robert Debré, APHP, Paris, France.

Pauline Krug: Nephrology Departement, Hôpital Necker Enfants Malades, APHP, Paris, France.

Violaine Lefranc: Paediatric Emergencies Departement, Centre Hospitalier Universitaire La Miletrie, Poitiers, France.

Catherine Didier-Wright: Paediatric Department, Centre Hospitalier de la Région Annecienne, Pringy, France.

Christine Pietremont: Nephrology Department, American Mémorial Hospital, Reims, France.

Amélie Ryckewaert: Paediatric Nephrology Departement, Centre Hospitalier Universitaire Rennes, Rennes, France.

Françoise Broux: Paediatric Nephrology Departement, Centre Hospitalier Universitaire Charles Nicolle, Rouen, France.

Marie-Pierre Lavocat: Paediatric Departement, Hôpital Nord, Centre Hospitalier Universitaire de Saint Etienne, Saint Etienne, France.

Joelle Terzic: Paediatric Departement, Centre Hospitalier Universitaire de Strasbourg, Strasbourg, France.

Stéphane Decramer: Pediatric Nephrology Department, Centre Hospitalier Universitaire de Toulouse, Toulouse, France.

Hubert Nivet: Pediatric Nephrology Department, Centre Hospitalier Universitaire de Tours, Tours, France.

Isabelle Vrillon: Paediatric Nephrology Departement, Hôpitaux de Brabois, Centre Hospitalier Universitaire de Nancy, Vandoeuvre Les Nancy, France.

\section{Acknowledgements}

We thank Eve Robinson and Athinna Nisavanh for their review of this manuscript. 
Conflict of interest

None declared.

\section{Authors' contributions}

Data collection: PM, SLH, SL, MG, MPD, EL, DST, CL, SB, FXW, members of the Réseau français hospitalier de surveillance du SHU pédiatrique.

Drafting of the analysis plan: MB, DVC, HDV, AM, NJ, LAK.

Statistical analysis: MB, DVC.

Review of draft versions of the manuscript and contribution to the final version: all authors.

\section{References}

1. Tarr PI, Gordon CA, Chandler WL. Shiga-toxin-producing Escherichia coli and haemolytic uraemic syndrome. Lancet. 2005;365(9464):1073-86. https://doi.org/10.1016/S01406736(05)71144-2 PMID: 15781103

2. Rosales A, Hofer J, Zimmerhackl LB, Jungraithmayr TC, Riedl M, Giner T, et al. Need for long-term follow-up in enterohemorrhagic Escherichia coli-associated hemolytic uremic syndrome due to late-emerging sequelae. Clin Infect Dis. 2012;54(10):1413-21. https://doi.org/10.1093/cid/cis196 PMID: 22412065

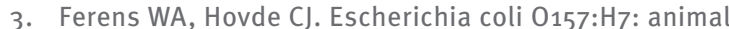
reservoir and sources of human infection. Foodborne Pathog Dis. 2011;8(4):465-87. https://doi.org/10.1089/fpd.2010.0673 PMID: 21117940

4. Bibbal D, Loukiadis E, Kérourédan M, Ferré F, Dilasser F, Peytavin de Garam C, et al. Prevalence of carriage of Shiga toxin-producing Escherichia coli serotypes $0_{157}: \mathrm{H}_{7}, \mathrm{O}_{2} 6: \mathrm{H}_{11}$, 0103:H2, O111:H8, and 0145:H28 among slaughtered adult cattle in France. Appl Environ Microbiol. 2015;81(4):1397-405. https://doi.org/10.1128/AEM.03315-14 PMID: 25527532

5. Kintz E, Brainard J, Hooper L, Hunter P. Transmission pathways for sporadic Shiga-toxin producing E. coli infections: A systematic review and meta-analysis. Int J Hyg Environ Health. 2017;220(1):57-67. https://doi.org/10.1016/j.ijheh.2016.10.011 PMID: 27842895

6. Vaillant V, Espié E, de Valk H, Durr U, Barataud D, Bouvet $P$, et al. Undercooked ground beef and person-to-person transmission as major risk factors for sporadic hemolytic uremic syndrome related to Shiga-toxin producing Escherchia coli infections in children in France. Pediatr Infect Dis J. 2009;28(7):650-3. https://doi.org/10.1097/ INF.obo13e3181993731 PMID: 19483660

7. Tuttle J, Gomez T, Doyle MP, Wells JG, Zhao T, Tauxe RV, et al. Lessons from a large outbreak of Escherichia coli 0157: $\mathrm{H}_{7}$ infections: insights into the infectious dose and method of widespread contamination of hamburger patties. Epidemiol Infect. 1999;122(2):185-92. https://doi.org/10.1017/ S0950268898001976 PMID: 10355781

8. Majowicz SE, Scallan E, Jones-Bitton A, Sargeant JM, Stapleton J, Angulo FJ, et al. Global incidence of human Shiga toxinproducing Escherichia coli infections and deaths: a systematic review and knowledge synthesis. Foodborne Pathog Dis. 2014;11(6):447-55. https://doi.org/10.1089/fpd.2013.1704 PMID: 24750096

9. Bruyand M, Mariani-Kurkdjian P, Gouali M, de Valk H, King LA, Le Hello S, et al. Hemolytic uremic syndrome due to Shiga toxin-producing Escherichia coli infection. Med Mal Infect. 2018;48(3):167-74. https://doi.org/10.1016/j. medmal.2017.09.012 PMID: 29054297

10. Sodha SV, Heiman K, Gould LH, Bishop R, Iwamoto M, Swerdlow DL, et al. National patterns of Escherichia coli 0157 infections, USA, 1996-2011. Epidemiol Infect. 2015;143(2):26773. https://doi.org/10.1017/S0950268814000880 PMID: 24731294

11. Ong KL, Apostal M, Comstock N, Hurd S, Webb TH, Mickelson $\mathrm{S}$, et al. Strategies for surveillance of pediatric hemolytic uremic syndrome: Foodborne Diseases Active Surveillance Network (FoodNet), 2000-2007. Clin Infect Dis. 2012;54(Suppl 5):S424-31. https://doi.org/10.1093/cid/cis208 PMID: 22572665

12. European Food Safety Authority (EFSA) and European Centre for Disease Control and Prevention (ECDC). The European Union summary report on trends and sources of zoonoses, zoonotic agents and food-borne outbreaks in 2015. Parma and Stockholm: EFSA and ECDC; 2016. Available from: http://ecdc. europa.eu/en/publications/Publications/EU-summary-reporttrends-sources-zoonoses-2015.pdf

13. Espié E, Grimont F, Mariani-Kurkdjian P, Bouvet $P$, Haeghebaert $S$, Filliol I, et al. Surveillance of hemolytic uremic syndrome in children less than 15 years of age, a system to monitor 0157 and non-0157 Shiga toxin-producing Escherichia coli infections in France, 1996-2006. Pediatr Infect Dis J. 2008;27(7):595601. https://doi.org/10.1097/INF.obo13e31816a062f PMID: 18520972

14. Bruyand M, Mariani-Kurkdjian P, Bonacorsi S, Gouali M, Le Hello S, Van Cauteren D, et al. Surveillance du syndrome hémolytique et urémique post-diarrhéique chez l'enfant de moins de 15 ans en France en 2015. [Surveillance of hemolytic and uremic post-diarrheal syndrome in children under 15 years in France in 2015]. Saint-Maurice: Santé publique France [Public Health France]; 2018. French. Available from: http://www. invs.sante.fr/Dossiers-thematiques/Maladies-infectieuses/ Risques-infectieux-d-origine-alimentaire/Syndromehemolytique-et-uremique/Donnees-epidemiologiques-du-SHUchez-l-enfant-age-de-moins-de-15-ans-en-France

15. Institut Pasteur. Centre National de Référence des Escherichia coli, Shigella et Salmonella. Paris: Institut Pasteur. [Accessed 1 Nov 2018]. Available from: https:// www.pasteur.fr/fr/sante-publique/CNR/les-cnr/ escherichia-coli-shigella-salmonella

16. Machado J, Grimont F, Grimont PA. Identification of Escherichia coli flagellar types by restriction of the amplified fliC gene. Res Microbiol. 2000;151(7):535-46. https://doi.org/10.1016/So9232508(00)00223-0 PMID: 11037131

17. Coimbra RS, Grimont $F$, Lenormand $P$, Burguière $P$, Beutin $L$, Grimont PA. Identification of Escherichia coli 0 -serogroups by restriction of the amplified 0 -antigen gene cluster (rfb-RFLP). Res Microbiol. 2000;151(8):639-54. https://doi.org/10.1016/ So923-2508(00)00134-0 PMID: 11081579

18. International Organization for Standardization (ISO). ISO/ TS 13136:2012. Microbiology of food and animal feed. Real $\square$ time polymerase chain reaction (PCR) Dbased method for the detection of food $\square$ borne pathogens. Horizontal method for the detection of shiga toxin producing Escherichia coli (STEC) and the determination of $0_{157,} \mathrm{O}_{111}, \mathrm{O}_{26}, \mathrm{O}_{103}$ and $\mathrm{O}_{145}$ serogroups. Geneva: ISO; 2012.

19. King LA, Nogareda F, Weill FX, Mariani-Kurkdjian P, Loukiadis E, Gault G, et al. Outbreak of Shiga toxin-producing Escherichia coli $0_{104}: \mathrm{H}_{4}$ associated with organic fenugreek sprouts, France, June 2011. Clin Infect Dis. 2012;54(11):1588-94. https://doi.org/10.1093/cid/cis255 PMID: 22460976

20. Frank C, Werber D, Cramer JP, Askar M, Faber M, an der Heiden $M$, et al. Epidemic profile of Shiga-toxin-producing Escherichia coli 0104:H4 outbreak in Germany. N Engl J Med. 2011;365(19):1771-80. https://doi.org/10.1056/NEJMoa1106483 PMID: 21696328

21. Ribot EM, Fair MA, Gautom R, Cameron DN, Hunter SB, Swaminathan B, et al. Standardization of pulsed-field gel electrophoresis protocols for the subtyping of Escherichia coli 0157:H7, Salmonella, and Shigella for PulseNet. Foodborne Pathog Dis. 2006;3(1):59-67. https://doi.org/10.1089/ fpd.2006.3.59 PMID: 16602980

22. Institut national de la statistique et des études économiques (Insee). [Accessed 11 Nov 2018]. Available from: https://www. insee. $\mathrm{fr} / \mathrm{fr} / \mathrm{accueil}$

23. Santé publique France [Public Health France]. Episode de cas groupés de syndromes hémolytiques et urémiques (SHU) et de diarrhées sanglantes survenus dans le Sud-Ouest, Juin 2012. Bilan au 18 juillet 2012. [Episode of group cases of haemolytic and uremic syndromes (HUS) and bloody diarrhea occurring in the South-West, June 2012. Update on July 18, 2012]. SaintMaurice: Santé publique France; 2012. Available from: http:// invs.santepubliquefrance.fr/Dossiers-thematiques/Maladiesinfectieuses/Risques-infectieux-d-origine-alimentaire/ Syndrome-hemolytique-et-uremique/Actualites/Archives/ Episode-de-cas-groupes-de-syndromes-hemolytiques-eturemiques-SHU-et-de-diarrhees-sanglantes-survenus-dansle-Sud-Ouest-Juin-2012.-Bilan-au-18-juillet-2012. Accessed on $11 / 01 / 2018$

24. King LA, Loukiadis E, Mariani-Kurkdjian P, Haeghebaert $\mathrm{S}$, Weill FX, Baliere C, et al. Foodborne transmission of sorbitol-fermenting Escherichia coli $0_{157}$ : $\left.\mathrm{H}_{7}\right]$ via ground beef: an outbreak in northern France, 2011. Clin Microbiol Infect. 2014;20(12):01136-44. https://doi.org/10.1111/14690691.12736 PMID: 24962059

25. Haut Conseil de la Santé Publique. [High Council of Public Health]. Gastroentérites à Escherichia coli entérohémorragique. [Enterohaemorrhagic Escherichia coli gastroenteritis]. [Accessed 11 Nov 2018]. Available from: http:// www.hcsp.fr/Explore.cgi/avisrapportsdomaine?clefr $=494$ 
26. King LA, Mailles A, Mariani-Kurkdjian P, Vernozy-Rozand C, Montet MP, Grimont F, et al. Community-wide outbreak of Escherichia coli 0157: $\mathrm{H}_{7}$ associated with consumption of frozen beef burgers. Epidemiol Infect. 2009;137(6):889-96. https://doi.org/10.1017/So950268808001490 PMID: 18945376

27. Ministère de l'agriculture et de l'alimentation [Ministery of Agriculture and Food]. Production de viandes hachées et préparations de viande dans les établissements agréés ou dérogataires à l'agrément. [Production of minced meat and meat preparations in establishments approved or derogated from approval]. [Accessed 11 Nov 2018]. French. Available from: https://info.agriculture.gouv.fr/gedei/site/bo-agri/ instruction-2015-507

28. Soysal N, Mariani-Kurkdjian P, Smail Y, Liguori S, Gouali M, Loukiadis E, et al. Enterohemorrhagic Escherichia coli Hybrid Pathotype 080:H2 as a New Therapeutic Challenge. Emerg Infect Dis. 2016;22(9):1604-12. https://doi.org/10.3201/ eid2209.160304 PMID: 27533474

29. Gould LH, Bopp C, Strockbine N, Atkinson R, Baselski V, Body $B$, et al. Recommendations for diagnosis of shiga toxin-producing Escherichia coli infections by clinical laboratories. MMWR Recomm Rep. 2009;58(RR-12):1-14. PMID: 19834454

30. Holmes A, Allison L, Ward M, Dallman TJ, Clark R, Fawkes A, et al. Utility of Whole-Genome Sequencing of Escherichia coli O157 for Outbreak Detection and Epidemiological Surveillance. J Clin Microbiol. 2015;53(11):3565-73. https://doi.org/10.1128/ JCM.01066-15 PMID: 26354815

\section{License, supplementary material and copyright}

This is an open-access article distributed under the terms of the Creative Commons Attribution (CC BY 4.0) Licence. You may share and adapt the material, but must give appropriate credit to the source, provide a link to the licence and indicate if changes were made.

Any supplementary material referenced in the article can be found in the online version.

This article is copyright of the authors or their affiliated institutions, 2019. 